\title{
Effects of Selected Pranayams on Breath-Holding Capacity, Cardio-Vascular Endurance \& Reaction Time of High School Students in Punjab
}

\author{
Dr. Bhupinder Singh Ghuman ${ }^{1,}$ Kuldip Singh ${ }^{2}$ \\ S.K.R. College of Physical Education, Bhagoo Majra, Kharar, S.A.S Nagar, Punjab, Indial \\ Govt. High School, Karala, S.A.S Nagar, Punjab, India
}

\begin{abstract}
The aim of the present study is to assess the effects of selected Pranayams on Breath-Holding Capacity, Cardio-Vascular Endurance \& Reaction Time of high school students in Punjab. Two hundred boy's age group of 13 to 16 years from Govt. High School, Karala, Punjab and S.B.W.S.M.P.School, Banur, Punjab were selected as the research subjects. The Pranayams Training duration was of 10-weeks. The subjects were divided into two groups as experimental (Group A) and control (Group B). The experimental group underwent Pranayams Training for 10-weeks and control group did not receive the Pranayams Training. The 't' test was used to compare pre and post-training values. After10-weeks Pranayams Training there was a significant $(P<0.001)$ difference between pre and post-testing of experimental group for the breath-holding capacity (pre = $35.89 \pm 1.55$, post $=36.92 \pm 1.57$ ), cardio-vascular endurance (pre $=1710.27 \pm 50.73$, post $1785.51 \pm 78.24$ ) and reaction time (pre $=24.81 \pm 0.40$, post $23.55 \pm 0.43$ ) as well as control group for the breath-holding capacity (pre $=34.28 \pm 1.01$, post $=34.27 \pm 1.02)$, cardio-vascular endurance $($ pre $=1580.94 \pm 13.62$, post $=1498.17 \pm 62.78)$ and reaction time ( pre $=25.90 \pm 0.50$, post $=25.83 \pm 0.52$ ). The experimental group had a significant improvement on Breath-Holding Capacity, Cardio-Vascular Endurance \& Reaction Time than the control group.
\end{abstract}

\section{Introduction}

Yoga is a scientific way of life, founded by Patanjali having its origin in India from thousands of years ago. But only Rishis and Munis practised it in ancient times. The word Yoga is derived from the Sanskrit word Yuj, literally meaning union- the union of soul. It is interpreted as the internal and external integration of a human being. Yoga can control the human mind, helps to gain proper knowledge by leaving the wrong things, calms the mind and raises concentration level. Yoga can improve strength, endurance and flexibility. In fact it is a beautiful way of living. The human mind and human body are intimately linked. If muscles are relaxed, then mind must be relaxed. If the mind is anxious then the body suffers too. All actions originate in the mind. Human life is full of hustle and bustle. The mind is continuously bombarded with stress. This unnecessary stress not only results a lot of discomfort but also damages energy and major cause of tiredness and illness.

There are eight-limbs of yoga mentioned in Patanjali's system. Pranayama is the fourth part of the eight-fold yoga. It is an easier way of understanding and realizing the dimensions of consciousness. The word 'prana' is a combination of two syllables pra and $n a$ and denotes constancy, being a force in constant motion. Whereas prana is the vital force, Pranayama is the process by which the internal pranic store is increased. Some people split the word 'Pranayama' Into prana and yama and define it as 'breath control'. However, it actually comprises the words prana and ayama which means 'pranic capacity or length'. Pranayama is a technique through which the quantity of prana in the body is activated to a higher frequency. By practising Pranayama certain amount of heat or creative force is generated throughout the entire body, influencing the existing quantum or prana. The science of Pranayama is based on retention of prana or kumbhaka towards this end. Due to fear of death even Brahma, the Lord of creation, keeps practicing Pranayama and so do many Yogis and Munis. Hence, it is recommended always to control the breath. "Even Brahma and other Gods in heaven devote themselves to practising Pranayama because it ends the fear of death". (Svatmarama, 1985). The mortals should follow the same path and control the breath. It may be the origin of Pranayama. Breath is life. Without food or water life is possible, but without breathing it's not. There is a close link between breath and soul. Pranayama is a complex act in which after assuming a suitable posture the person inhales and exhale slowly, deeply and completely.

\section{Objectives of the study}

1. To assess the effects of selected Pranayams on Breath-Holding Capacity of high school students in Punjab.

2. To assess the effects of selected Pranayams on Cardio-Vascular Endurance of high school students in Punjab.

3. To assess the effects of selected Pranayams on Reaction Time of high school students in Punjab. 


\section{Material And Methods}

This study was designed to evaluate the effects of 10-weeks daily practice [Except Sunday and holidays]. Effects of selected Pranayams on Breath-Holding Capacity, Cardio-Vascular Endurance \& Reaction Time of high school students. Two hundred students, aged 13 to 16 years, studying in $6^{\text {th }}$ to $10^{\text {th }}$ class high school students were included. Groups of healthy students with no history of present and past illness were selected. Student' $t$ ' test was used to see the significant of mean differences between pre-test and post-test values.

\section{Results \& Conclusions}

Computed' $\mathrm{t}$ ' Ratio to see the Significance of Differences between Pre-Test and Post-Test Means of Experimental Group and the Control Group with regard to Breath-Holding Capacity has been in table-1.

\begin{tabular}{|l|c|c|c|c|c|c|}
\hline Group & Number & Mean & S.D. & SEM & 't' Value & P-value \\
\hline Experimental (Pre-test) & 100 & 35.89 & 1.55 & 0.15 & $5.46^{*}$ & 0.0001 \\
Experimental (Post-test) & 100 & 36.92 & 1.57 & 0.15 & & \\
\hline Control (Pre-test) & 100 & 34.28 & 1.01 & 0.10 & 0.17 & 0.8626 \\
Control (Post-test) & 100 & 34.27 & 1.02 & 0.09 & & \\
\hline
\end{tabular}

$\mathrm{t}_{05}(99)=1.65$

Table-1 presents the results of experimental group and the control group with regard to the variable Breath-Holding Capacity. The descriptive statistics shows the Mean and SD values of Breath-Holding Capacity of pre-test and post-test of experimental group was $35.89 \pm 1.55$ and $36.92 \pm 1.57$ respectively, whereas the Mean and SD values of Breath-Holding Capacity of pre-test and post-test of control group was $34.28 \pm 1.01$ and $34.27 \pm 1.02$. The " $\mathrm{t}$ " value in case of experimental group was 5.46* and for control group it was 0.17 . The " $\mathrm{t}$ " value in case of experimental group 5.46* as shown in the table was found statistically significant as it was greater than the table value of $\mathrm{t}=1.65$ which shows that Breath-Holding Capacity of the experimental group was improved due to 10-weeks training of selected pranayams. But in case of control group there was no improvement in the Breath-Holding Capacity as the calculated value of $t=0.17$ was less than the table value required to be significant at .05 level of significance.

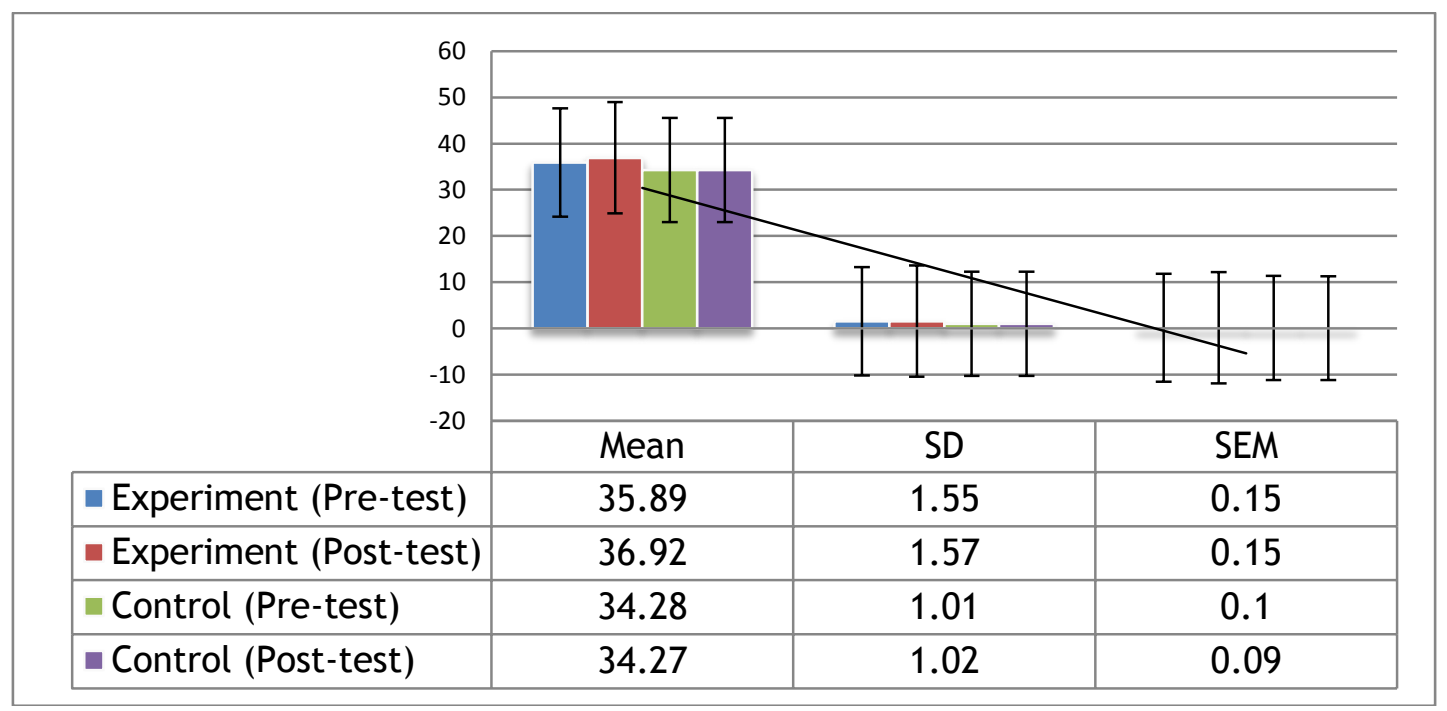

Figure-1. Mean, Standard Deviation (SD), Standard Error of Mean (SEM) of Breath-Holding Capacity of Experimental and Control Group.

Computed ' $t$ ' ratio to see the Significance of Differences between Pre-Test and Post-Test Means of Experimental Group and the Control Group with regard to Cardio-Vascular Endurance has been in table 2.

\begin{tabular}{|l|c|c|c|c|c|c|}
\hline Group & Number & Mean & S.D. & SEM & 't' Value & P-value \\
\hline Experiment (Pre-test) & 100 & 1710.27 & 50.73 & 5.07 & $8.15^{*}$ & 0.0001 \\
Experimental (Post-test) & 100 & 1785.51 & 78.24 & 7.82 & \multirow{2}{*}{$12.86^{*}$} & 0.0001 \\
\cline { 1 - 5 } Control (Pre-test) & 100 & 1580.94 & 13.62 & 1.36 & \\
Control (Post-test) & 100 & 1498.17 & 62.78 & 6.27 & & \\
\hline
\end{tabular}

$\mathrm{t}_{.05}(99)=1.65$

Table-2 presents the results of experimental group and the control group with regard to the variable CardioVascular Endurance. The descriptive statistics shows the Mean and SD values of Cardio-Vascular Endurance of 
pre-test and post-test of experimental group was $1710.27 \pm 50.73$ and $1785.51 \pm 78.24$, respectively whereas the Mean and SD values of Cardio-Vascular Endurance of pre-test and post-test of control group was $1580.94 \pm 13.62$ and $1498.17 \pm 62.78$. The " $t$ " value in case of experimental group was $8.15^{*}$ and for control group it was 12.86 . The " $t$ "-value in case of experimental group $8.15^{*}$ as shown in the table was found statistically significant as it was greater than the table value of $t=1.65$, which shows that Cardio-Vascular Endurance of the experimental group was improved due to 10-weeks training of selected pranayams. In case of control group there was also a significant difference. But when we see the mean values, it is found that there was a decrease in the mean value of post-test that may be one of the reasons for this type of results.

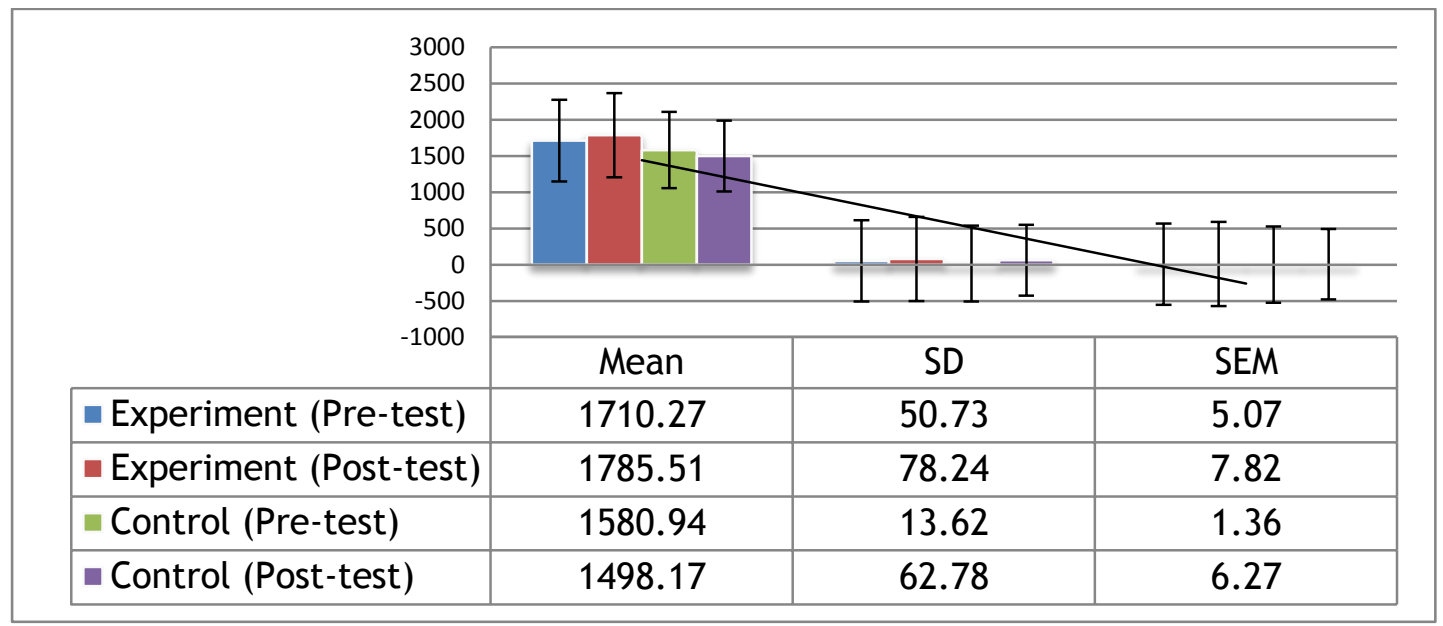

Figure-2. Mean, Standard Deviation (SD), Standard Error of Mean (SEM) of cardio-vascular endurance of Experimental and Control Group.

Computed ' $t$ ' Ratio to see the Significance of Differences between Pre-Test and Post-Test Means of Experimental Group and the Control Group with regard to Reaction Time has been in table 3.

\begin{tabular}{|l|c|c|c|c|c|c|}
\hline Group & Number & Mean & S.D. & SEM & 't' Value & P-value \\
\hline Experiment (Pre-test) & 100 & 24.81 & 0.40 & 0.04 & $12.66^{*}$ & 0.0001 \\
Experimental (Post-test) & 100 & 23.55 & 0.43 & 0.04 & & \\
\hline Control (Pre-test) & 100 & 25.90 & 0.50 & 0.05 & 1.51 & 0.1345 \\
Control (Post-test) & 100 & 25.83 & 0.52 & 0.05 & & \\
\hline
\end{tabular}

t.05 (99) $=1.65$

Table- 3 presents the results of experimental group and the control group with regard to the variable Reaction Time. The descriptive statistics shows the Mean and SD values of Reaction Time of pre-test and posttest of experimental group was $24.81 \pm 0.40$ and $23.55 \pm 0.43$ respectively, whereas the Mean and SD values of Reaction Time of pre-test and post-test of control group was $25.90 \pm 0.50$ and $25.83 \pm 0.52$. The "t" value in case of experimental group was $12.66 *$ and for control group it was 1.51 . The " $t$ "-value in case of experimental group $12.66^{*}$ as shown in the table was found statistically significant as it was greater than the table value of $\mathrm{t}=1.65$, which shows that Reaction Time of the experimental group decreased due to 10 -weeks training of selected Pranayams. But in case of control group there was no decrease in the Reaction Time as the calculated value of $\mathrm{t}=1.51$ was less than the table value required to be significant at .05 level of significance.

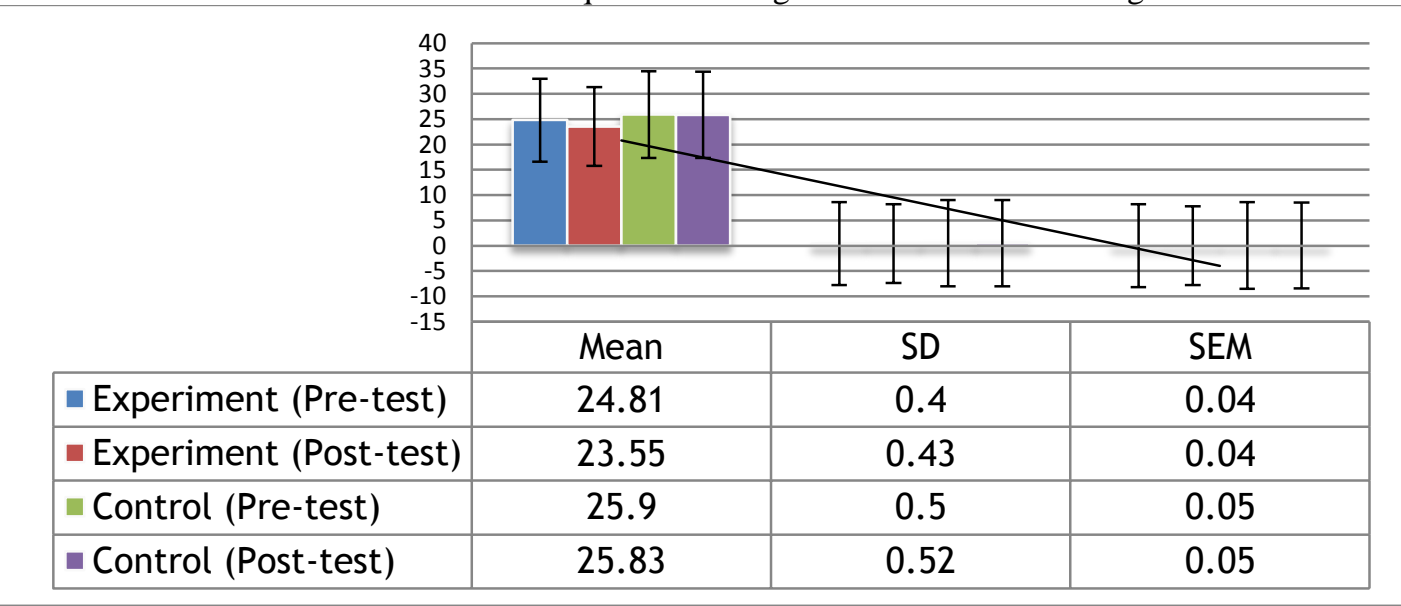




\section{Figure-3. Mean, Standard Deviation (SD), Standard Error of Mean (SEM) of Reaction Time of Experimental and Control Group.}

\section{Discussion}

The study was aimed to find out the effects of selected Pranayams on Breath-Holding Capacity, CardioVascular Endurance \& Reaction Time of high school students in Punjab. Results pertaining to Breath Holding Capacity showed that there were significant differences between pre and post-test for experimental group and for control group it was found insignificant, which indicates that there was a significant role of paranayams on Breath-Holding Capacity of high school students, the findings are in line with the findings of Dabal (2003) who investigated the relationship of Breath-Holding Capacity with pulmonary function and reported in his findings significant relationship between Breath-Holding Capacity with Pulmonary Function of male students.

In a different study Upadhyay et al. (2008) also reported same type of results; they studied the effects of Pranayams on Breath-Holding Capacity and found significant relationship between Pranayams and BreathHolding Capacity of the subjects. Sisodia and Tomar (2009) in their investigation found contradict results, as they reported that there was no significant effect of Anuloma-Viloma Pranayama on Breath-Holding time.

The results pertaining to the Cardio-Vascular Endurance showed that there was significant difference found between pre and post-test for experimental group and for control group it was found insignificant, which indicates that there was a significant role of Pranayams on Cardio-Vascular Endurance of high school students, the findings are supported by the findings of Ganguly and Gharate (1974) who studied the effects of yogic training on Cardio-Vascular Efficiency of male students and reported daily one hour of yogic training improved cardio-vascular efficiency of the subjects.

In a different study, Lolage and Berra (1999) conducted a study to find out the effects of Pranayams on CardioVascular Endurance of Kho-Kho players and reported in their findings that Pranayams were useful in improving Cardio-Vascular Endurance of Kho-Kho players. Udupa et al. (2003) also conducted a study to see the effects of Pranayams training on Cardiac Function of young person's; they found Pranayams Training modulates ventricular performance by increasing Parasympathetic Activity and decrease Sympathetic Activity.

Mohan et al. (2005) in their study worked to find out the effects of Slow and Fast Pranayams on CardioRespiratory Function and concluded that different types of Pranayams produce different physiological response in normal young persons. Abraham (2000) investigated the effects of different Pranayams techniques on CardioRespiratory Endurance and reported no significant relationship between Pranayams and Cardio-Respiratory Endurance his findings are contradicts our findings.

The results pertaining to the Reaction Time showed that there was a significant difference between pre and posttest for experimental group and for control group it was found insignificant, which indicates that there was a significant role of Paranayams on Reaction Time of high school students, the findings are supported by the findings of Mohan et al. (1992) who worked to find out the effects of Yoga Training on Reaction Time, they documented in their findings that there was significant relation of Yoga training with the Reaction Time. This finding is in line with the findings of our study. Udupa et al. (2005) also conducted a study to find out the effects of different Pranayams techniques on Reaction Time, they reported that there was a significant effects of Pranayams technique on Reaction Time and supports our findings.

\section{Conclusions}

On the basis of the obtained results the following conclusions were drawn:-

1. The results suggest that 10 -weeks training programme of selected Pranayams improved Breath-Holding Capacity of high school students. There is a significant role of Pranayams to improve our BreathHolding Capacity.

2. It is also concluded that 10 -weeks training programme of selected Pranayams improved CardioVascular Endurance of high school students.

3. It is further concluded that training programme of 10-weeks of selected Pranayams improved Reaction Time of high school students.

On the final note, it can conclude that regular practice of Pranayams is helpful to improve Breath-Holding Capacity, Cardio-Vascular Endurance \& Reaction Time. Thus it is suggested that to be in good shape of health status, one must regularly practice yogic asanas and pranayams.

\section{References}

[1] Joshi, K.S, Yogic Pranayama, Orient Paperbacks, New Delhi, Page.10, 1982.

[2] Svatmarama, Hatha-Yoga-Pradipika, with a commentary by Swami MuktibodhanandaSaraswati.Munger, Bihar, India: Bihar School of Yoga, Page. 203, 1985.

[3] Best, J.W, and Kahn, J.V., Research in Education. PHI Pvt. Ltd. New Delhi, Edition Tenth, Page. 483.2010.

[4] Dabal, "The Relationship of Breath Holding Capacity to Selected Pulmonary Functions." Unpublished doctoral Thesis, Lakshmibai National Institute of Physical Education, Gwalior, 2003

[5] Upadhyay, D. K., "Effects or Alternate Breathing Exercise on Cardio-Respiratory Functions.” Nepal Med Journal, 2008, 10:1. PP. 257. 
[6] Sisodia, A.S, and Tomar, S.S, "Effects of Anuloma- VilomaPranayama on Selected Respiratory Variable." Journal of Health, Physical Education \& Sports, 2009, 1:1.

[7] Ganguly, S.K., and Gharate, "The Effects of Yogic Training of Cardio-Vascular Efficiency before and after Yogic Training." Yoga Mimamsa, 1974, Vol. XVIII, No. 1, 89-97.

[8] Lolage, R.S, \& Berra, "Effects of Pranayama on Cardio-Respiratory Endurance of Kho-Kho Players." Paper presented in $3^{\text {rd }}$ International conference on Yoga research and tradition, 1999,

[9] Udupa, K., "Effects of Pranayama Training on Cardiac Function in Normal Young Volunteers." Indian Journal of Physiology Pharmacology, 2003, 47:1, PP. 27-33.

[10] Mohan, M., and Udupa, "Effects of Slow and Fast Pranayams on Reaction Time and Cardio-Respiratory Variables." Indian Journal of Physiology Pharmacology, 2005, 49:3, PP. 313-8.

[11] Abraham, M., "The comparative effects of Kapalbhati, Suryabhendna and their Combination on Cardio-Respiratory Endurance and Selected Physiological Variables."Unpublished doctoral Thesis, Lakshmibai National Institute of Physical Education, Gwalior, 2000.

[12] Mohan, M., and Thombre, D.P., “Effects of Yoga Trainingon Reaction Time, Respiratory Endurance and Muscle Strength.” Indian Journal of Physiology Pharmacology, 1992, 36:4, PP. 229-33. 